\title{
Effects of papaverine and carbon dioxide alone or in combination on the blood flow of internal thoracic artery
}

Ismail Koramaz, MD, ${ }^{a}$ Mehmet Ozkan, MD, ${ }^{c}$ Gokalp Altun, MD, ${ }^{a}$ Kibar Yasar Guven, MD, ${ }^{a}$ Mine Kadioglu Duman, MD, Nuri Ihsan Kalyoncu, MD, ${ }^{\mathrm{b}}$ Ersin Yaris, MD, PhD, ${ }^{\mathrm{b}}$ and Fahri Ozcan, $\mathrm{MD}^{\mathrm{a}}$

Objective: The internal thoracic artery is frequently used as an arterial graft for coronary bypass. Spasms of internal thoracic artery may contribute to early myocardial ischemia. To prevent vasospasm and increase the blood flow, some vasodilatory agents (such as carbon dioxide or papaverine) are used. The aim of the study was to evaluate the combined effects of carbon dioxide and papaverine versus either alone on the blood flow of the internal thoracic artery.

Methods: One hundred patients undergoing coronary artery bypass grafting (28 women and 72 men) with similar characteristics were randomly divided into four groups. We used the classic technique without any vasodilatory management before surgery in group 1, papaverine injection into the endothoracic fascia in group 2, and carbodissection technique in groups 3 and 4 . Initial free flows of the internal thoracic arteries were measured after cutting of the vessel. After the first measurement, the ITA pedicles were washed with papaverine solution and wrapped with gauze in the first and fourth groups. Blood flow measurements were repeated 15 minutes later in all groups.

Results: When vasodilatory management was applied during excision, the blood flows were significantly increased relative to group 1 . The mean blood flows reached a significantly higher level in groups 1, 2, 3, and 4 at the second measurements. In groups 2 and 3, the increase at the first measurements compared to the first group's level was continuously high, but no additional increase was observed between the first and second measurements. In groups 1 and 4, regardless of whether a previous vasodilatory management was present, the increases measured at repeated measurements were significant versus each group's first measurements $(P<.05)$.

Conclusions: Vasodilatory management, such as injection of papaverine into endothoracic fascia or carbon dioxide insufflation applied during excision, increased the

From the Departments of Cardiovascular Surgery $^{\mathrm{a}}$ and Pharmacology, ${ }^{\mathrm{b}}$ Karadeniz Technical University, School of Medicine, Trabzon, Turkey, and the Department of Cardiovascular Surgery, Camlica Omur Hospital, Istanbul, Turkey. ${ }^{\mathrm{c}}$

Received for publication May 16, 2006; revisions received June 30, 2006; accepted for publication July 17, 2006.

Address for reprints: Ismail Koramaz, MD, Karadeniz Technical University, School of Medicine, Department of Cardiovascular Surgery, TR-61187 Trabzon, Turkey (E-mail: ismailkoramaz@yahoo.com).

J Thorac Cardiovasc Surg 2006;132:1126-30 $0022-5223 / \$ 32.00$

Copyright $(\odot) 2006$ by The American Association for Thoracic Surgery

doi:10.1016/j.jtcvs.2006.07.015 free blood flows of internal thoracic artery pedicles. Exogenously applied papaverine produces an additional and continuous vasodilatation regardless of whether a vasodilatory intervention was previously applied.

$\mathrm{T}$ he left internal thoracic artery (ITA) is one of the most commonly used arterial bypass grafts in myocardial revascularization. Its clinical superiority to saphenous vein grafts has been shown to be tremendous in terms of long-term patency and low incidence of graft degeneration, even in end-stage coronary artery disease. ${ }^{1-3}$

Perioperative spasm of the ITA is a common problem in coronary artery bypass grafting (CABG). Spasms of ITA may contribute to early myocardial ischemia, increasing perioperative morbidity and mortality, in addition to hypoperfusion syndrome, as manifested by left ventricular failure and increased pulmonary wedge pressure, which is related to inadequate blood flow through arterial grafts. ${ }^{4-7}$ A graft spasm or a further reduction in arterial graft flow may be caused by surgical trauma 


\section{Abbreviations and Acronyms \\ $\mathrm{CABG}=$ coronary artery bypass grafting \\ ITA $=$ internal thoracic artery}

to the endothelium, which leads to a serious thromboxane $\mathrm{A}_{2}$ release from activated platelets or by catecholamines produced in excessive amounts during surgical stress induced by $\mathrm{CABG}$ or by administered drugs. ${ }^{8}$ Vasospasm of the ITA seen at the early period after operation or a decrease in blood flow as a result of intimal proliferation or atherosclerosis seen years after operation can cause hazardous results in $\mathrm{CABG}$ patients. ${ }^{9}$

ITA may be harvested and used as pedicled, skeletonized, or free grafts. All these methods aim to increase the arterial capacity of blood flow and avoid vasospasm. To prevent vasospasm during or after surgical intervention and increase blood flow, some vasodilatory agents (such as carbon dioxide or papaverine) can be used.

The aim of this study was to compare the free flow capacities of ITA grafts prepared by classic harvesting, by injection of papaverine into endothoracic fascia, or by carbodissection techniques. This study also aimed to evaluate the effects of carbon dioxide and papaverine in combination or alone on the blood flow of ITA and a possible additional contribution from exogenously applied papaverine.

\section{Patients and Methods \\ Patients}

After the local (Karadeniz Technical University School of Medicine) research ethics committee approval (No. 2004/10) was obtained, 100 patients with coronary artery disease who had no exclusion criteria and who would undergo elective, isolated, primary CABG operation were selected from the waiting list. They were assigned by a random number generator into classic (group 1), papaverine (group 2) and carbodissection (groups 3 and 4) groups. Each group included 25 patients (Table 1). The demographic variables did not show any significant difference between groups.

\section{Operative Technique}

All patients were given $1 \mathrm{mg}$ alprazolam (Xanax; Eczacibasi, Istanbul, Turkey) orally for sedation the night before the surgery. The radial artery blood pressure was monitored in all cases. Anesthesia was induced with $30-\mu \mathrm{g} / \mathrm{kg}$ fentanyl citrate and $0.1-\mathrm{mg} / \mathrm{kg}$ midazolam and maintained with $0.3-\mu \mathrm{g} /(\mathrm{kg} \cdot \mathrm{min})$ fentanyl citrate and $0.8-\mu \mathrm{g} /(\mathrm{kg} \cdot \mathrm{min})$ midazolam infusions. After the anesthesia, a standard median sternotomy was performed.

In the first group, ITAs were harvested by classic pedicled technique. A small incision was made into the endothoracic fascia medial to the ITA pedicle and adjacent to the superior border of a costal cartilage. Dissection of the pedicle was completed by continuing the incision in the endothoracic fascia through the length of the pedicle with scissors, and the pedicle was gently separated from the chest wall by blunt dissection. To identify the ITA branches, clips were applied to the artery. Before the ITA harvesting in the second group, papaverine $(10 \mathrm{mg}$ papaverine in $20 \mathrm{~mL}$ saline solution) was injected to the endothoracic fascia adjacent to the surgical area. ${ }^{10}$ Before the ITA harvesting in the third and fourth groups, carbon dioxide was suffused to the endothoracic fascia with a flow rate of 4 to $6 \mathrm{~L} / \mathrm{min} .{ }^{11,12}$ To avoid thermal injury while harvesting the ITAs, electrocautery was never used. All ITAs were harvested in a pedicled manner.

Heparin $(300 \mathrm{U} / \mathrm{kg}$ ) was administered intravenously 3 minutes before the transection of the ITA. The first free flow was calculated by leaving the artery bleeding for a minute after cutting the distal end of the vessel. During the flow measurements, the heart rate, arterial systolic and diastolic pressures, and mean arterial pressures were recorded. In the first and fourth groups, after the first measurements, the ITAs were washed with papaverine solution (10 mg papaverine in $20 \mathrm{~mL}$ saline solution) and wrapped with gauze. In all groups, second measurements were taken 15 minutes after cutting the artery (just before CPB). All these cases involved anastomosis of the left anterior descending artery with a left ITA.

\section{Statistical Analysis}

Data are presented as mean $\pm \mathrm{SD}$. The paired $t$-test was used for comparisons between first and second measurements in each group. The $\chi^{2}$ test was used for comparisons of the groups according to sex. The alterations in blood flow rates between the groups were evaluated by 1-way analysis of variance (ANOVA). The Tukey post hoc test was then used to compare ITA flows between the groups.

TABLE 1. Patient demographic, preoperative, and perioperative data

\begin{tabular}{lccccc}
\hline Variable & Group 1 & Group 2 & Group 3 & Group 4 & P value \\
\hline Sex (female/male) & $7: 18$ & $8: 17$ & $6: 19$ & .941 \\
Age (y) & $59.3 \pm 10.9$ & $61.4 \pm 12.6$ & $60.2 \pm 10.0$ & $58.4 \pm 10.7$ \\
BSA (m ${ }^{2}$ ) & $1.8 \pm 0.1$ & $1.8 \pm 0.1$ & $1.8 \pm 0.1$ & $1.8 \pm 0.1$ & .81 \\
HR 1 (beats/min) & $72.1 \pm 8.7$ & $71.3 \pm 8.9$ & $72.2 \pm 7.4$ & $72.4 \pm 7.0$ & .857 \\
HR 2 (beats/min) & $70.5 \pm 9.3$ & $70.6 \pm 7.1$ & $72.4 \pm 6.0$ & .971 \\
MAP 1 (mm Hg) & $71.6 \pm 4.8$ & $72.1 \pm 6.5$ & $71.8 \pm 6.9$ & $72.0 \pm 7.1$ & .594 \\
MAP 2 (mm Hg) & $71.4 \pm 5.0$ & $72.0 \pm 6.0$ & $71.4 \pm 6.8$ & $71.6 \pm 6.0$ & .995 \\
\hline
\end{tabular}

Data are presented as mean \pm SD. The paired $t$-test was used for comparisons between first and second measurements in each group and the $\chi^{2}$ test was used for comparison of the groups according to sex. BSA, Body surface area; $H R$, heart rate; $M A P$, mean arterial pressure. 


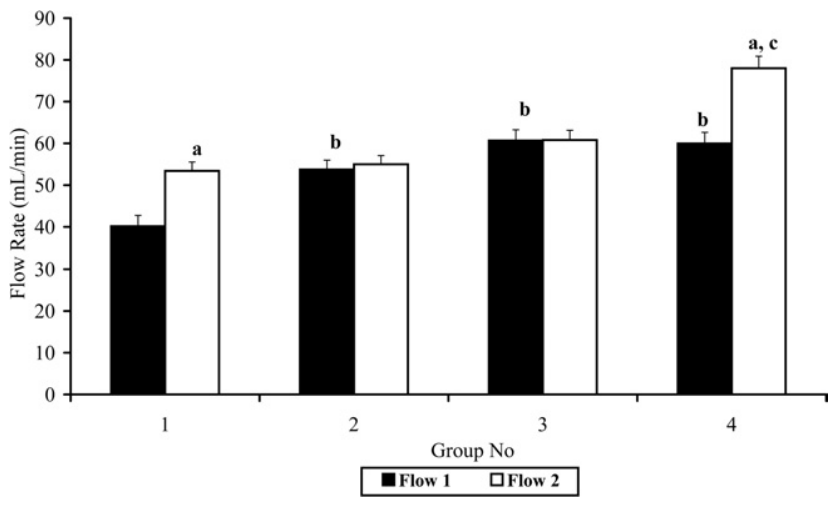

Figure 1. Effects of papaverine and carbon dioxide on first (black bars) and second (white bars) flow rates of internal thoracic artery in experimental groups. Values are presented as mean \pm SD ( $\mathrm{n}=25$ in each group). $\boldsymbol{a}, \boldsymbol{P}<.05$ versus first measurement in each group; $b, P<.05$ versus first measurement in group 1; $c, P<$ .05 versus second measurements of groups 1,2 , and 3 .

\section{Results}

The demographic and hemodynamic data are shown in Table 1. There were no significant alterations in heart rate and mean arterial pressure during the first and second measurements of blood flow. No patient had perioperative myocardial infarction. There were no significant differences in the use of inotropic agents and postoperative drainage between patient groups. In our study, all patients had spontaneous return of sinus rhythm. We did not observe any serious complications, such as pleural effusion, and all patients were discharged after a postoperative observation period.

In the first measurement, the mean blood flows of ITA were $40.2 \pm 13.0,53.8 \pm 11.2,60.7 \pm 13.0$, and $60.0 \pm$ $13.4 \mathrm{~mL} / \mathrm{min}$ in groups $1,2,3$, and 4 , respectively. When vasodilatory management (injection of papaverine into endothoracic fascia or carbon dioxide insufflation) was applied during excision, the blood flows were significantly increased relative to group 1 , which was harvested by classic technique without any vasodilatory management. The mean blood flows reached significantly higher levels in the second measurements of $53.4 \pm 10.7,55.0 \pm 10.4,60.8 \pm$ 11.7 , and $78.0 \pm 14.4 \mathrm{~mL} / \mathrm{min}$ in groups $1,2,3$, and 4 , respectively. In groups 2 and 3, in which papaverine alone was injected before harvesting or carbon dioxide alone was applied, the increase in the first measurements relative to the group 1's level were high in a continuous and stable manner, but no additional increase was observed between the first and second measurements. In the exogenous papaverine groups, independent of previous vasodilatory treatment (groups 1 and 4), the increases in the blood flows obtained at repeated measurements were continuous and statistically significant relative to each group's first measurements $(P<$ .05; Figure 1).

\section{Discussion}

Although the long-term patency of ITA grafts is generally accepted, and they are the first choice for coronary conduits, spasm of ITA after CABG can be seen as with other grafts. ${ }^{1-3}$ ITA spasms may contribute to early myocardial ischemia, increasing perioperative morbidity and mortality. In addition, inadequate blood flow through arterial grafts may cause a hypoperfusion syndrome manifested by left ventricular failure, increasing pulmonary wedge pressure, and cardiac arrest. ${ }^{13}$

Because ITA is sensitive to trauma, which can lead to arterial spasm, some precautions are taken to prevent such spasms. The increased release of various vasoconstricting substances, such as sympathetic amines ${ }^{14}$ and the decrease in the amount of vasodilators (such as nitric oxide), probably caused by trauma especially to the endothelial layer of the artery, which is the main source of such endogenous vasodilatory factors, ${ }^{15}$ are at the heart of this vasoconstriction.

One of the vasodilatory managements that can be applied during harvesting is carbon dioxide insufflation. ${ }^{11}$ This method depends on iatrogenic emphysema induced by carbon dioxide insufflated into the endothoracic fascia. This carbodissection technique gives a proper medium for the surgeon at the harvesting course with a better visualization. It was reported that a better exploration could protect the arterial branches from trauma and consequent spasm, help the surgeon in gentle excision. ${ }^{11,12}$

Koramaz and colleagues ${ }^{16}$ reported that carbon dioxide insufflation protected the integrity of whole vessel and prevented the possible vasospasm of the artery, mainly as a result of its effect on endothelial function. Ozkan and associates $^{17}$ reported in a previous study that carbon dioxide insufflation alone increased the free flow rate of ITA relative to both its own control and topical papaverine alone. In this study, we observed that carbon dioxide insufflation before harvesting increased the flow rate of ITA in both the first and second measurements in group 3 relative to group 1 's measurement without any vasodilatory management before harvesting. This increase was also valid in the first measurement of group 4. On the basis of the nearly equal results of the first and second measurements in group 3, we can say that this prominent effect of carbon dioxide is stable and permanent. The vasodilatory effect of carbon dioxide was long lasting. In an in vitro study by Koramaz and colleagues, ${ }^{16}$ the protective effect of carbon dioxide for endothelium-dependent relaxation was still seen nearly 3 to 4 hours after insufflation in the operating room.

Known negative effects of arterial spasms have forced surgeons to develop new techniques (modified pedicled, skeletonized, carbodissection techniques) and use some drugs (calcium-channel blockers, phosphodiesterase inhibitors) to avoid arterial spasm or intimal damage. One of these drugs is papaverine, which is a potent vasodilatory agent mostly 
used to protect against arterial spasm in CABG patients. Papaverine directly dilates the smooth muscle of the arteries. This vasodilatory effect is not dependent on endothelium and factors released from the endothelial layer. In addition, a synergistic action of papaverine comes from its calcium-channel blocking, adenosine-uptake blocking, and phosphodiesterase-inhibiting effects. Papaverine may be used in different routes of administration, such as injection into the endothoracic fascia before harvesting, ${ }^{10}$ periarterial injection to the pedicle, and intraluminal injection or topical administration to the pedicle by washing with the drug and wrapping with gauze washed by papaverine. ${ }^{18}$ Although Takeuchi and colleagues ${ }^{19}$ and other authors ${ }^{20}$ have shown papaverine injection to increase free flow rates of ITA, in our study we did not use papaverine intraluminally, because its acidic nature can cause endothelial cell damage in addition to its possible mechanical injury effect on the endothelial layer. ${ }^{21}$

In this study, papaverine injection into the endothoracic fascia in group 2 improved the first and second measurements of flow rates relative to the first measurement in the first group without any vasodilatory management. The increase caused by this method was stable and permanent in group 2 , because there was not any difference between the first and second measurements of ITA flow rate in the patients of group 2. But Girard and coworkers ${ }^{22}$ reported that injection of papaverine into the endothoracic fascia did not improve flow rate. It can be suggested that this difference between their results and our own may be related to the different characteristics of our patient populations. Any of the variables of our patients did not differ among patient groups, and it can be accepted that the groups are well matched (Table 1). But in Girard and coworkers' patient groups, ${ }^{22}$ there are some limitations such as randomization, uniformity, and sample size.

Topically applied papaverine washing and wrapping the artery also improved the ITA flow rate. This significant improvement is seen especially in group 1 between the first and second measurements, when the artery was harvested without any vasodilatory agent. Such a dramatic increase is also seen in group 4, in which carbon dioxide was applied. In this group, an additional improvement was obtained by topical papaverine. Carbon dioxide caused a steady increase in flow rates in group 3, and a more prominent and significant increase was induced by topical papaverine in addition to carbon dioxide in group 4.

The mechanism of this improvement with papaverine is mainly its vasodilatory effect. Papaverine is a potent vasodilatory drug used in human beings for different indications. Injection of the drug to the endothoracic fascia clearly improves the flow rate in group 2. But topical application of the drug is also capable of the increase in flow rates seen in group 1. The same route of application makes an addi- tional contribution in carbon dioxide-insufflated patients. All these results show that topically administrated papaverine, whether from washing or wrapping the artery diffuses to the arterial tissue.

In conclusion, it can be said that any perioperative vasodilatory management, whether systemic or local, provides improvements in the flow rates of ITA. The application of each vasodilatory agent, carbon dioxide and papaverine, can increase the flow rates of the grafts through different mechanisms. When they are applied together, a better improvement can be observed from the additive interaction of these agents through the combined actions of their own different effects.

We thank Gamze Can, MD, for statistical analysis.

\section{References}

1. Loop FD, Lytle BW, Cosgrove DM, Stewart RW, Goormastic M, Williams GW, et al. Influence of the internal mammary artery graft on 10-year survival and other cardiac events. N Engl J Med. 1986;314: $1-6$.

2. Olearchyk AS, Magovern GJ. Internal mammary artery grafting: clinical results, patency rates and long-term survival in 833 patients. J Thorac Cardiovasc Surg. 1986;92:1082-7.

3. Cameron AC, Green GE, Brogno DA, Thornton J. Internal thoracic artery grafts: 20-year clinical followup. J Am Coll Cardiol. 1995;25: 188-92.

4. Sarabu MR, McClung J, Fass A, Reed GE. Early postoperative spasm in the left internal mammary artery bypass grafts. Ann Thorac Surg. 1987;44:199-200.

5. Jones EL, Lattouf OM, Weinstraub WS. Catastrophic consequences of internal mammary artery hypoperfusion. J Thorac Cardiovasc Surg. 1989;98:902-7.

6. Suma H. Spasm of the right gastroepiploic artery. Ann Thorac Surg. 1990;49:168-9.

7. Parise LV, Venton DL, Le Breton GC. Arachidonic acid-induced platelet aggregation is mediated by a thromboxane A2/prostaglandin receptor interaction. J Pharmacol Exp Ther. 1984;228:240-4.

8. Becker KP, Garnovskaya M, Gettys T, Halushka PV. Coupling of thromboxane A2 receptor isoforms to Galpha13: effects on ligand binding and signalling. Biochim Biophys Acta. 1999;1450:288-96.

9. Cracowski JL, Stanke-Labesque F, Chavanon O, Blin D, Mallion JM, Bessard G, Devillier P. Vasorelaxant actions of enoximone, dobutamine, and the combination on human arterial coronary bypass grafts. J Cardiovasc Pharmacol. 1999;34:741-8.

10. Mulay AV, Dev KK, Nair RU. Prevention of internal thoracic artery spasm. Ann Thorac Surg. 1997;64:564.

11. Lee ME. Carbodissection of the internal thoracic artery pedicle. Ann Thorac Surg. 1988;46:470-1

12. Ozkan M, Aslan A, Oguz M, Yildirim C, Oktar L, Ergul G, et al. A carbon dioxide insufflation technique for preparation of the internal thoracic artery. J Thorac Cardiovasc Surg. 2003;125:963-4.

13. Jones EL, Lattouf OM, Weinstraub WS. Catastrophic consequences of internal mammary artery hypoperfusion. $J$ Thorac Cardiovasc Surg. 1989;98:902-7.

14. Sogo N, Campanella C, Webb DJ, Megson IL. S-nitrosothiols cause prolonged, nitric oxide-mediated relaxation in human saphenous vein and internal mammary artery: therapeutic potential in bypass surgery. Br J Pharmacol. 2000;131:1236-44.

15. He GW, Yang CQ, Star A. Overview of the nature of vasoconstriction in arterial grafts for coronary operations. Ann Thorac Surg. 1995;59: 676-83.

16. Koramaz I, Ozkan M, Kesim M, Guven KY, Kadioglu M, Ulku C, et al. The contracting and relaxing responses of human internal mammary artery grafts harvested by two different methods. Pharmacol Res. 2005;51:567-73. 
17. Ozkan M, Koramaz I, Ulus AT, Tavil Y, Filizlioglu H, Baykan EC, et al. Effect of carbon dioxide insufflation on free internal thoracic artery flows: is it a vasodilator? J Thorac Cardiovasc Surg. 2004;28: 354-6.

18. Sasson L, Cohen AJ, Hauptman E, Schachner A. Effect of topical vasodilators on internal mammary arteries. Ann Thorac Surg. 1995; 59:494-6.

19. Takeuchi K, Sakamoto S, Nagayoshi Y, Nishizawa H, Matsubara J. Reactivity of the human internal thoracic artery to vasodilators in coronary artery bypass grafting. Eur J Cardiothorac Surg. 2004;26:956-9.
20. Vilandt J, Kjaergard H, Aggestrup S, Andreasen JJ, Olesen A. Intraluminal papaverine with $\mathrm{pH} 3$ doubles blood flow in the internal mammary artery. Scand Cardiovasc J. 1999;33:330-2.

21. van Son JA, Tavilla G, Noyez L. Detrimental sequelae on the wall of the internal mammary artery caused by hydrostatic dilatation with diluted papaverine solution. J Thorac Cardiovasc Surg. 1992;104: 972-6.

22. Girard DS, Sutton JP 3rd, Williams TH, Crumbley AJ 3rd, Zellner JL, Kratz JM, et al. Papaverine delivery to the internal mammary artery pedicle effectively treats spasm. Ann Thorac Surg. 2004;78:1295-8. 